\title{
RELUCTANCE NETWORK MODEL OF A PERMANENT MAGNET TUBULAR MOTOR
}

\author{
Andrzej WAINDOK*, Bronisław TOMCZUK \\ *Opole University of Technology, Department of Industrial Electrical Engineering \\ ul. Prószkowska 76, 45-758 Opole, Poland \\ a.waindok@po.opole.pl, b.tomczuk@po.opole.pl
}

received 10 October 2016, revised 29 July 2017 2017, accepted 16 August 2017

\begin{abstract}
The reluctance network model of a permanent magnet tubular motor (PMTM) has been presented in the paper. The reluctance values of the magnetic circuit have been calculated with using analytical expressions. The air gap reluctance has been determined with using both analytical expressions and the finite element method (FEM). Using the calculation model, the flux values coupled with the windings have been obtained and used in the calculations of force value. The calculated results have been compared with numerical and measured ones.
\end{abstract}

Keywords: Reluctance Network Method, Tubular Linear Motors, Electrodynamic Force Calculation

\section{INTRODUCTION}

Linear electric motors, which convert electric energy directly into mechanical thrust, have become increasingly popular in many applications, such as manufacturing automation (Gieras et al., 2011), transportation (Gieras et al., 2011), power generation, fatigue testing of materials (Tomczuk and Waindok, 2009) etc. In Fig. 1a the permanent magnet tubular motor (PMTM) has been presented (Tomczuk et al., 2012). It has been used in a drive for fatigue test stand. It is an original construction developed in Department of Electrical Engineering and Mechatronics at Opole University of Technology.

There are many various calculation methods used in the analysis of PMTM (Gieras et al., 2011; Tomczuk et al., 2012). Nowadays, FEM method is widely used (Tomczuk et al., 2007). However, it demands the knowledge of the field theory for formulation of the boundary problems and application of a computer package dedicated for the magnetic field analysis. In order to formulate some hints for design (initial values for geometry) and for evaluation of the field analysis the analytical methods are needed (Chevailler et al., 2004). In case of tubular motors an analytical approach, which applies Fourier series is commonly used (Wang and Howe, 2005; Wang et al., 1998; 2003; Amara and Barakat, 2010; Bianchi, 2000; Boroujeni et al., 2009; Gysen et al., 2011). In case of flat linear motors, beside Fourier series (Chung and Gweon, 2002), the reluctance network model (RNM) is very often used (Batdorff and Lumkes, 2009; Kazan and Onat, 2011; Okonkwo, 2006; Polinder et al., 2003; Sheikh-Glalavand et al., 2010) including the Carter coefficient (Gieras et al., 2011). In the presented paper, the RNM method is used for the calculation of tubular motor. This method is understood by all who know the solving of circuits and is available for everybody because it does not demand some commercial computer applications. The execution time for this case is relatively short, as well.

\section{PHYSICAL MODEL}

The picture and cross section of the analyzed linear motor have been presented in Fig. 1. The definitions of main dimensions are given in Fig. 2. The parameters of the motor are given in Tabs. 1 and 2. The presented construction has been designed for fatigue testing of materials. Thus, it have to be characterized by high reliability and good dynamic properties. In order to achieve these requirements, the moving coil construction has been developed.
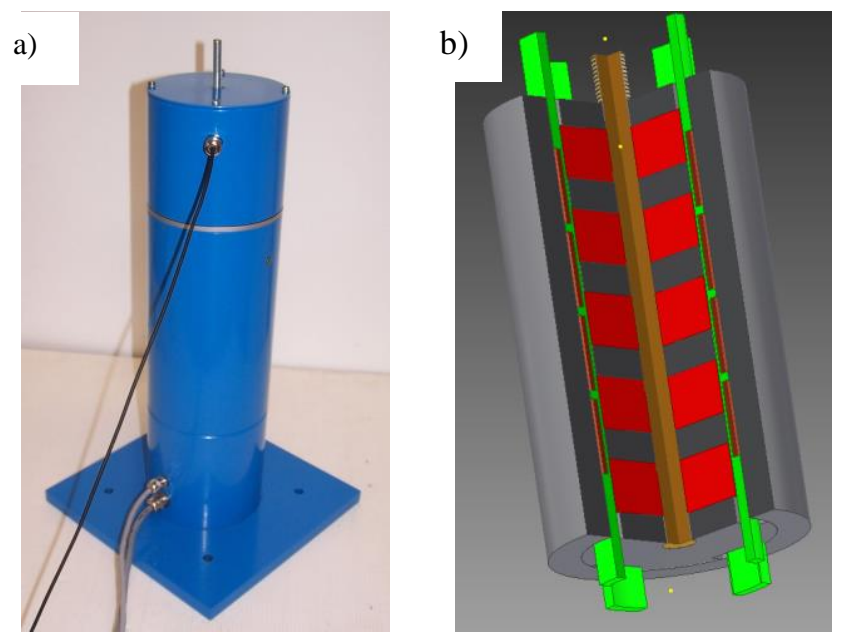

Fig. 1. a) Picture of the PMTM, b) Cross section 


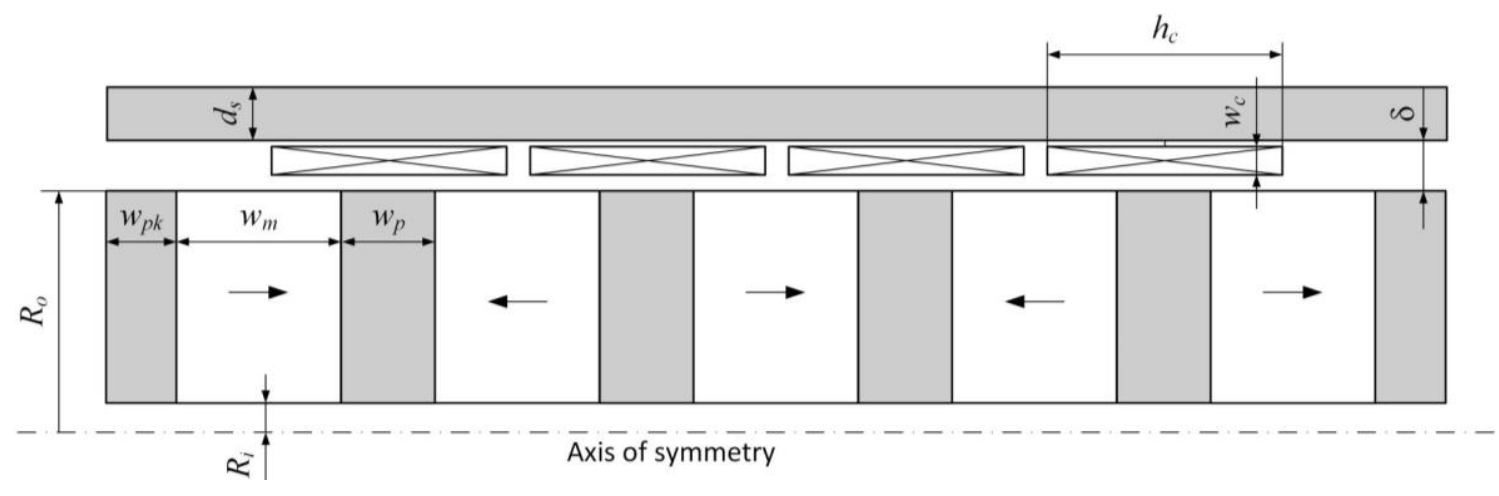

Fig. 2. Dimension symbols of the motor

Tab. 1. Dimensions of the PMTM

\begin{tabular}{|c|c|}
\hline Dimension symbol & Value [mm] \\
\hline$R_{i}$ & 8 \\
\hline$R_{o}$ & 40 \\
\hline$\delta$ & 6.8 \\
\hline$d_{s}$ & 16 \\
\hline$W_{p}$ & 15 \\
\hline$W_{p k}$ & 13 \\
\hline$W_{m}$ & 26 \\
\hline$W_{c}$ & 4 \\
\hline$h_{c}$ & 37 \\
\hline
\end{tabular}

Tab. 2. Main parameters of the PMTM

\begin{tabular}{|c|c|}
\hline Parameter & Value \\
\hline Nominal constant force [N] & 400 \\
\hline Maximum force [N] & 600 \\
\hline Nominal current [A] & 2.4 \\
\hline Maximum current [A] & 3.6 \\
\hline Nominal stroke [mm] & 15 \\
\hline Nominal frequency [Hz] & 50 \\
\hline
\end{tabular}

\section{RELUCTANCE NETWORK MODEL}

The RNM model of the PMTM is presented in Fig. 3a. The linear properties of the steel has been assumed. In order to determine the linear magnetic permeability, the nonlinear $\mathrm{B} / \mathrm{H}$ curve has been linearized (Fig. $3 \mathrm{~b}$ ). The value $\mu_{r}=434$ has been assumed and used in the RNM model.

The fluxes in the motor section are given in Fig. 4. In case of steel cores and permanent magnets, the reluctance values (Fig. 3a) for such elements can be calculated using the standard expressions:

- Permanent magnet reluctance

$R_{\mu m}=\frac{w_{m}}{\mu_{0} \mu_{r m} S_{m}}=\frac{0.026}{4 \pi \cdot 10^{-7} \cdot 1.048 \cdot 0.004825}=4.09 \cdot 10^{6} \frac{1}{\mathrm{H}}$

- Border ferromagnetic rings reluctance

$R_{\mu 1}=\frac{\ln \left(\frac{R_{O}+\delta+d_{S} / 2}{R_{i}}\right)}{\mu_{0} \mu_{r} 2 \pi w_{p}}=\frac{\ln \left(\frac{0.04+0.0068+0.008}{0.008}\right)}{4 \pi \cdot 10^{-7} \cdot 434 \cdot 2 \pi \cdot 0.013}=43.2 \cdot 10^{3} \frac{1}{\mathrm{H}}(2)$

- Outer stator reluctance

$R_{\mu 2}=\frac{w_{m}+w_{p}}{\mu_{0} \mu_{r} S}=\frac{0.026+0.015}{4 \pi \cdot 10^{-7} \cdot 434 \cdot 0.000551}=13.6 \cdot 10^{3} \frac{1}{\mathrm{H}}$
- Ferromagnetic rings reluctance

$R_{\mu 3}=\frac{\ln \left(\frac{R_{o}}{R_{i}}\right)}{\mu_{0} \mu_{r} 2 \pi w_{p}}=\frac{\ln \left(\frac{0.04}{0.008}\right)}{4 \pi \cdot 10^{-7} \cdot 434 \cdot 2 \pi \cdot 0.015}=31.3 \cdot 10^{3} \frac{1}{\mathrm{H}}$

where:

- The permanent magnet cross-section area equals the ring surface

$S_{m}=\pi \cdot\left(R_{o}^{2}-R_{i}^{2}\right)=\pi \cdot\left(0.04^{2}-0.008^{2}\right)=$ $4.825 \cdot 10^{-3} \mathrm{~m}^{2}$

- Outer stator cross-section area

$S=\pi \cdot\left(\left(R_{o}+\delta+d_{s}\right)^{2}-\left(R_{o}+\delta\right)^{2}\right)$

$=\pi \cdot\left(0.0628^{2}-0.0468^{2}\right)=5.509 \cdot 10^{-3} \mathrm{~m}^{2}$

In the case of calculation the air gap reluctance, which is relatively long, the leakage flux lines have to be taken into account (Fig. 4). The simple expression (Fig. 2, Tab. 1)

$R_{\mu \delta}=\frac{\ln \left(\frac{R_{O}+\delta}{R_{O}}\right)}{\mu_{0} 2 \pi w_{p}}=\frac{\ln \left(\frac{0.04+0.0068}{0.04}\right)}{4 \pi \cdot 10^{-7} \cdot 2 \pi \cdot 0.015}=1.326 \cdot 10^{6} \frac{1}{\mathrm{H}}$

doesn't give the correct value, which leads to calculation errors in magnetic flux determination. Thus, some calculations of the airgap reluctance have been carried out with using the finite element method (FEM). In Fig. 5, the simplified model of the air-gap and permanent magnet system, created in FEMM software, have been presented. It contains only two permanent magnets and one air gap. In Tab. 3 the dimensions of the model are given. In Figs. 6 and 7 the calculation results of the air gap reluctance have been presented. In case of FEM calculations both, linear (Fig. 7a) and nonlinear (Fig. 7b) magnetic materials were considered. Comparing Figs. $7 \mathrm{a}$ and $7 \mathrm{~b}$, it is visible that the properties of the steel does not influence the calculation results significantly. The differences do not exceed 1\% (Fig. 8a). Due to relatively huge air gap, its reluctance calculated from expression (7) (Fig. 6) is much higher, than the real one (Fig. 7). The differences exceed 100\% (Fig. 8b). Thus, a correction factor $\mathrm{k}$ has been introduced. Its value depends on the air gap and ferromagnetic ring dimensions (Fig. 9). In order to obtain more correct value of the reluctance, we should introduce the factor in the expression (7). After multiplication the expression (7) by this factor we obtain more precise result:

$R_{\mu \delta k}=k \cdot R_{\mu \delta}=0.5694 \cdot 1.326 \cdot 10^{6}=$

$754.8 \cdot 10^{3} \frac{1}{\mathrm{H}}$. 


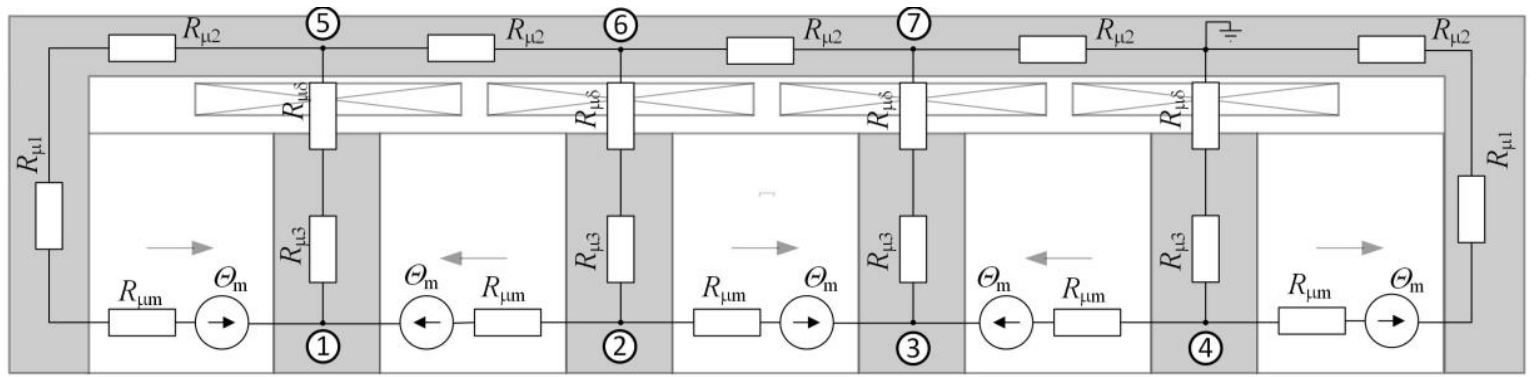

Axis of symmetry

Fig. 3a. The reluctance network model of the PMTM

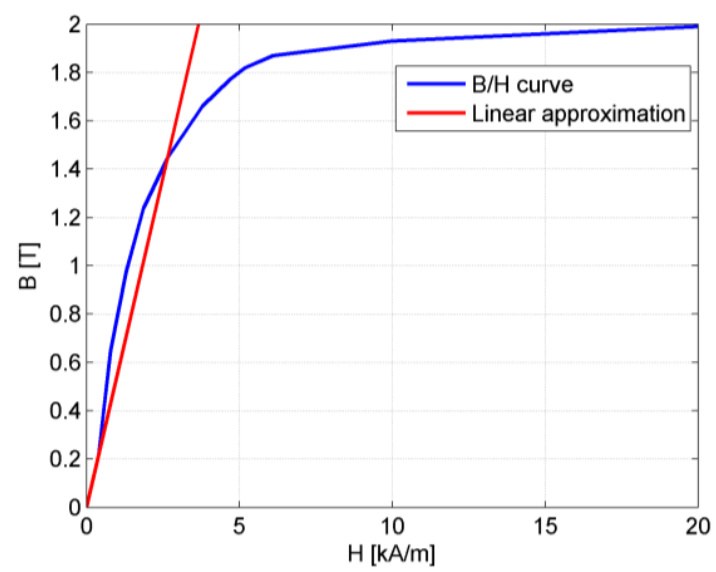

Tab. 3. Dimensions of the model in Fig. 5

\begin{tabular}{|c|c|}
\hline Dimension & Value [mm] \\
\hline$W_{p k}$ & 13 \\
\hline$W_{m}$ & 26 \\
\hline$d_{s}$ & 6 \\
\hline$R_{i}$ & 8 \\
\hline$R_{0}$ & 40 \\
\hline$W_{p}$ & $10 \div 20$ \\
\hline$\delta$ & $3 \div 10$ \\
\hline
\end{tabular}

Fig. 3b. Nonlinear B/H curve of the steel

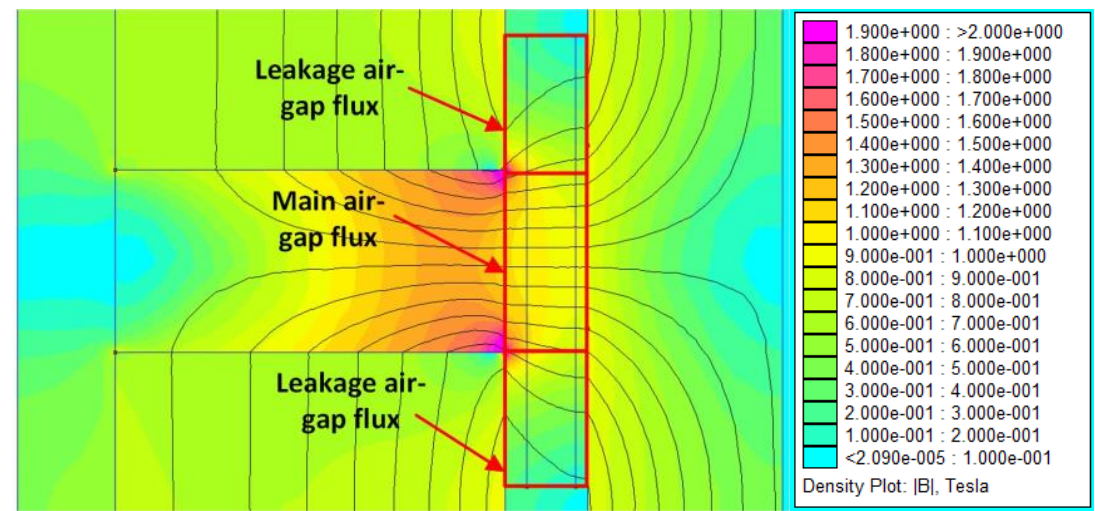

Fig. 4. Magnetic field distribution in the air gap of the PMTM
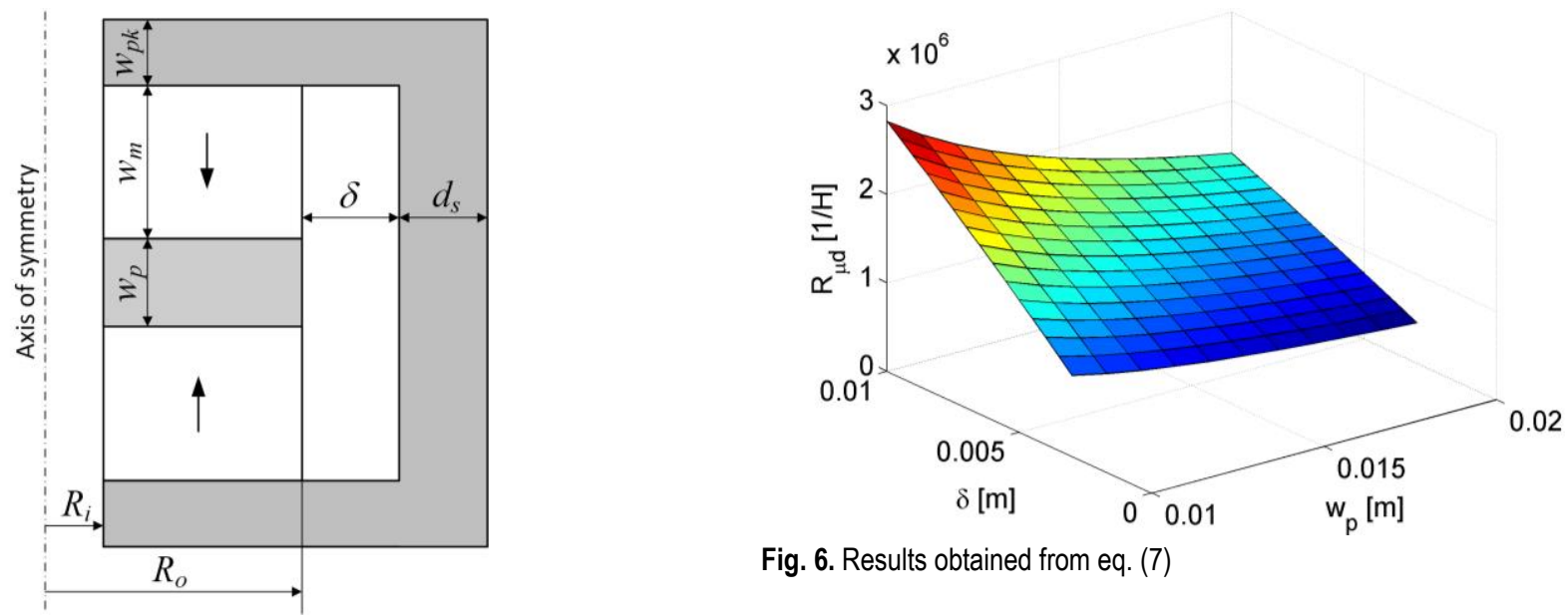

Fig. 6. Results obtained from eq. (7)

Fig. 5. Simplified model of an air-gap analyzed with using FEM 
a)

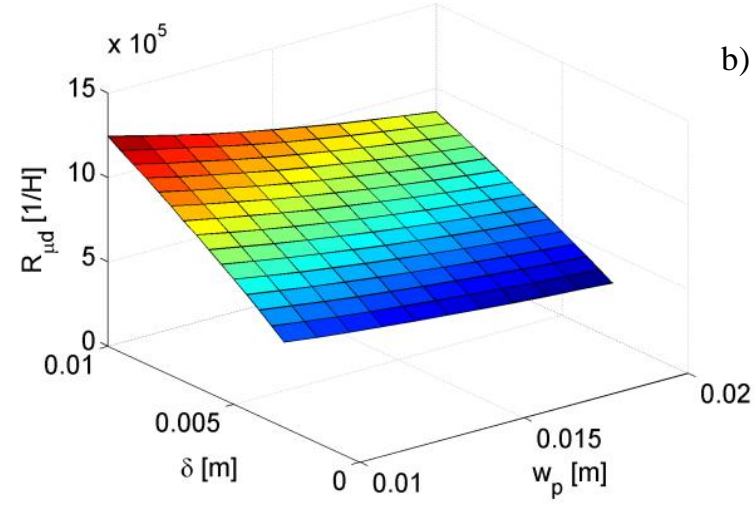

b)

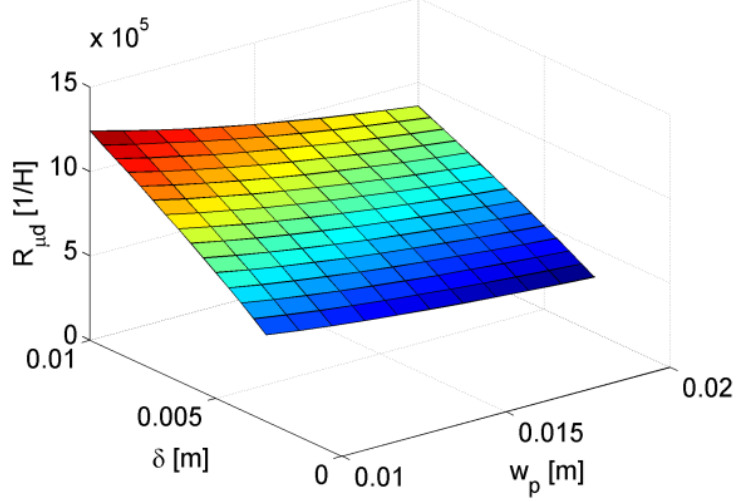

Fig. 7. Results from the FEM calculations: a) linear model, b) nonlinear model

a)

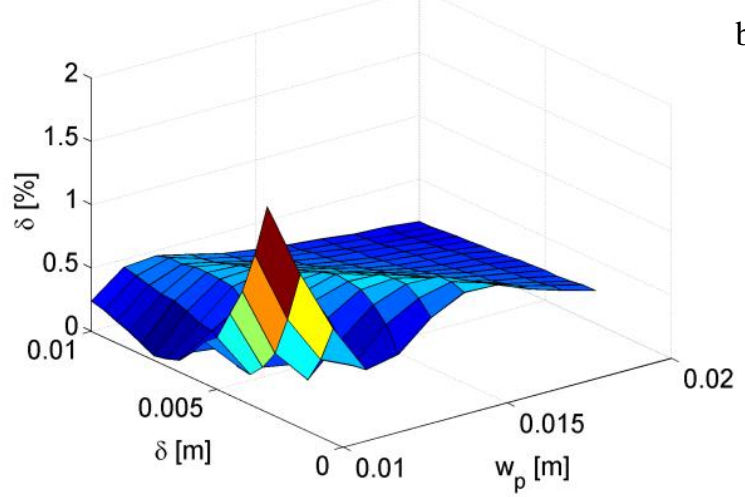

b)

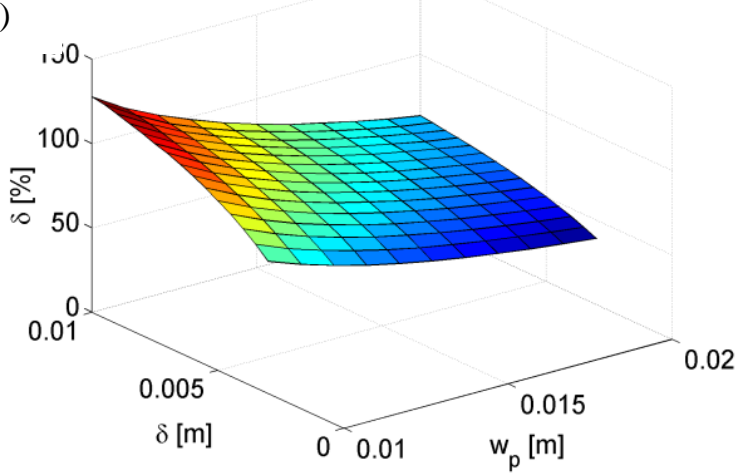

Fig. 8. Relative differences between: a) linear and nonlinear FEM models, b) nonlinear FEM and analytical models

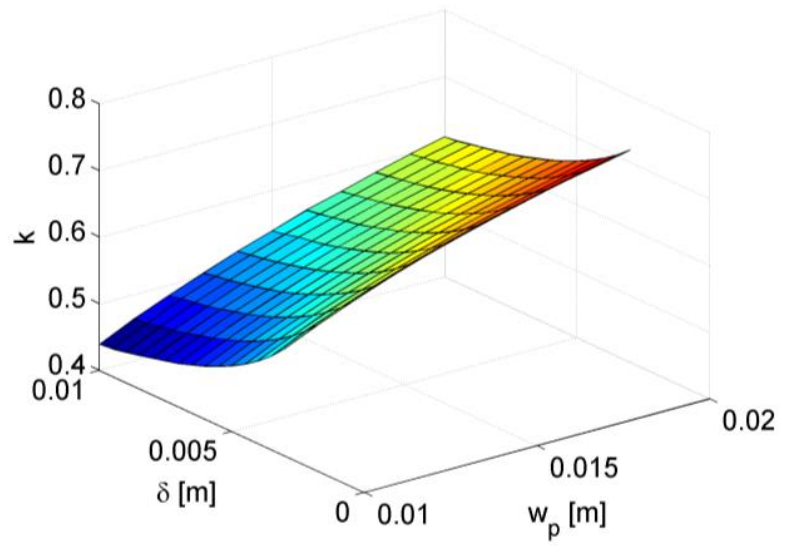

Fig. 9. Correction factor for the analytical model vs. $w_{p}$ and $\delta$ dimensions

For the magnetic flux determination, we need not only the reluctance values, but also the magnetomotive forces (MMF). The MMF force of the permanent magnets can be easy calculated using their coercive force $\mathrm{H}_{c}$ :

$$
\begin{aligned}
\Theta_{m}=w_{m} \cdot H_{c}= & 0.026[\mathrm{~m}] \cdot 950000\left[\frac{\mathrm{A}}{\mathrm{m}}\right] \\
& =24700 \mathrm{~A} .
\end{aligned}
$$

Due to a small value of the MMF of the excitation winding in comparison with the permanent magnet MMF, the former one has been neglected.

Using the magnetic potential method the linear system of equations could be formulated in matrix form (Fig. 3a):

$$
\begin{aligned}
& {\left[\begin{array}{lllllll}
G_{11} & G_{12} & 0 & 0 & G_{15} & 0 & 0 \\
G_{21} & G_{22} & G_{23} & 0 & 0 & G_{26} & 0 \\
0 & G_{32} & G_{33} & G_{34} & 0 & 0 & G_{37} \\
0 & 0 & G_{43} & G_{44} & 0 & 0 & 0 \\
G_{51} & 0 & 0 & 0 & G_{55} & G_{56} & 0 \\
0 & G_{62} & 0 & 0 & G_{65} & G_{66} & G_{67} \\
0 & 0 & G_{73} & 0 & 0 & G_{76} & G_{77}
\end{array}\right] \cdot\left[\begin{array}{l}
V_{\mu 1} \\
V_{\mu 2} \\
V_{\mu 3} \\
V_{\mu 4} \\
V_{\mu 5} \\
V_{\mu 6} \\
V_{\mu 7}
\end{array}\right]=} \\
& {\left[\begin{array}{l}
2 \Theta_{m} / R_{\mu m} \\
-2 \Theta_{m} / R_{\mu m} \\
2 \Theta_{m} / R_{\mu m} \\
-2 \Theta_{m} / R_{\mu m} \\
-\Theta_{m} / R_{\mu m} \\
0 \\
0
\end{array}\right],}
\end{aligned}
$$

where:

$G_{11}=G_{44}=\frac{1}{R_{\mu m}+R_{\mu 1}+R_{\mu 2}}+\frac{1}{R_{\mu 3}+R_{\mu \delta}}+\frac{1}{R_{\mu m}}$,

$G_{22}=G_{33}=\frac{1}{R_{\mu 3}+R_{\mu \delta}}+\frac{2}{R_{\mu m}}$,

$G_{55}=\frac{1}{R_{\mu m}+R_{\mu 1}+R_{\mu 2}}+\frac{1}{R_{\mu 3}+R_{\mu \delta}}+\frac{1}{R_{\mu 2}}$,

$G_{66}=G_{77}=\frac{1}{R_{\mu 3}+R_{\mu \delta}}+\frac{2}{R_{\mu 2}}$,

$G_{12}=G_{21}=G_{23}=G_{32}=G_{34}=G_{43}=-\frac{1}{R_{\mu m}}$,

$G_{15}=G_{51}=-\frac{1}{R_{\mu m}+R_{\mu 1}+R_{\mu 2}}-\frac{1}{R_{\mu 3}+R_{\mu \delta}}$, 
$G_{26}=G_{62}=G_{37}=G_{73}=-\frac{1}{R_{\mu 3}+R_{\mu \delta}}$,

$G_{56}=G_{65}=G_{67}=G_{76}=-\frac{1}{R_{\mu 2}}$.

After solution of the system above, the magnetic potential values in the nodes of the circuit in Fig. 3a were obtained. They are used for calculation of the fluxes in the motor magnetic circuit.

The electrodynamic force could be calculated from the simple expression:

$F=B I l$.

However, in our case it is difficult to including the magnetic flux density values by points. Thus we have used more proper and convenient expression with the total magnetic flux value

$F=\Phi \frac{I N}{h_{c}}$

In Fig. 10, the magnetic force values vs. the current intensity values, are presented. The results from linear RNM have been compared with the results from the finite element analysis and from the measurement results. A very good conformity between measurements and RNM calculation results is observed. The results from FEM method with nonlinear $\mathrm{B} / \mathrm{H}$ characteristic differ a little bit more from measurement values. However, the differences are not significant (less than 7\%).

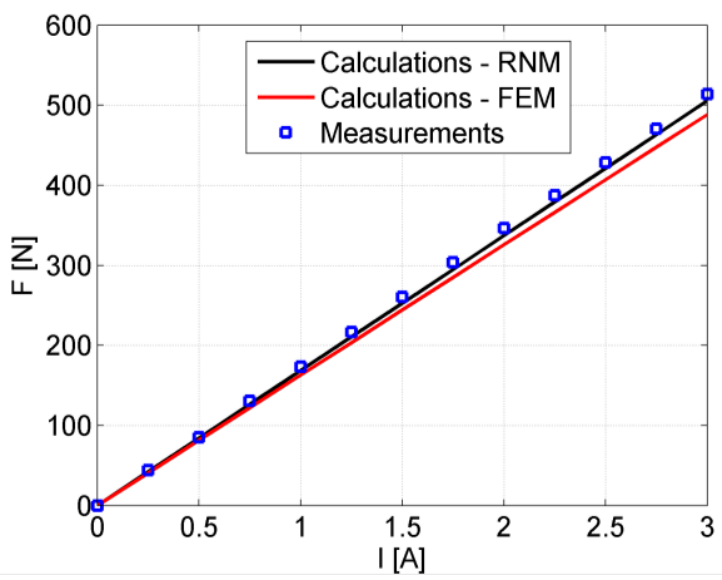

Fig. 10. Magnetic force vs. current value

\section{CONCLUSIONS}

In many cases, when we are designing an electromagnetic device with relatively big air gaps the magnetic reluctances can be calculated with analytical expressions. When the gaps are very small and the magnetic circuit shape is complicated the finite element method (FEM) should be used. Thus, in many cases the analytical models are a good alternative to the numerical ones. They are characterized by very short calculation time, under acceptable accuracy.

Of all the analytical methods, the reluctance network method (RNM) is easiest and simplest. For the presented PMTM calculations, it has only one disadvantage - the proper determination of the air-gap reluctance is quite difficult. It influences the results significantly. In the presented case of TLM (tubular linear motor) with relatively large air-gap, there is no correction coefficient (in the literature) for analytical calculation of the reluctance. In the paper, the FEM method has been used for determination of the correction coefficient.
Using the calculation model, the flux values coupled with the windings have been obtained and used in the calculations of the force value. The calculated results have been compared with numerical and measured ones. The measurement validation of the presented method confirms its correctness.

\section{REFERENCES}

1. Amara Y., Barakat G. (2010), Analytical modeling of magnetic field in surface mounted permanent-magnet tubular linear machines, IEEE Trans. on Magnetics, 46, 3870-3884.

2. Batdorff M.A., Lumkes J.H. (2009), High-fidelity magnetic equivalent circuit model for an axisymmetric electromagnetic actuator, IEEE Trans. on Magnetics, 45, 3064-3072.

3. Bianchi N. (2000), Analytical field computation of a tubular permanent-magnet linear motor, IEEE Trans. on Magnetics, 36, 3798-3801.

4. Boroujeni S.T., Milimonfared J., Ashabani M. (2009), Design, prototyping and analysis of a novel tubular permanent-magnet linear machine, IEEE Trans. on Magnetics, 45, 5405-5413.

5. Chevailler S., Markovic M., Jufer M., Perriard Y. (2004), Linear motor optimization using an analytical model, ICEM, Cracow, Poland, 5-8 September, paper no 311 (on conference CD).

6. Chung M.J., Gweon D.G. (2002), Modeling of the armature slotting effects in the magnetic field distribution of a linear permanent magnet motor, Electrical Engineering, 84, 101-108.

7. Gieras J.F., Piech Z.J., Tomczuk B. (2011), Linear synchronous motors, CRC Press, Taylor \& Francis Group, USA.

8. Gysen B.L.J., Meessen K.J., Paulides J.J.H., Lomonova E.A. (2011), 3-D analytical and numerical modeling of tubular actuators with skewed permanent magnets, IEEE Trans. on Magnetics, 47, 2200-2212.

9. Kazan E., Onat A. (2011), Modeling of air core permanent-magnet linear motors with a simplified nonlinear magnetic analysis, IEEE Trans. on Magnetics, 47, 1753-1762.

10. Okonkwo R.C. (2006), Design and performance of permanentmagnet DC linear motors, IEEE Trans. on Magnetics, 42, 2179-2183.

11. Polinder H., Slootweg J.G., Hoeijmakers M.J., Compter J.C. (2003), Modeling of a linear PM machine including magnetic saturation and end effects: maximum force-to-current ratio, IEEE Trans. on Magnetics, 39, 1681-1688.

12. Sheikh-Ghalavand B., Vaez-Zadeh S., Hassanpour Isfahani A. (2010), An improved magnetic equivalent circuit model for iron-core linear permanent-magnet synchronous motors, IEEE Trans. on Magnetics, 46, 112-120.

13. Tomczuk B., Schröder G., Waindok A. (2007), Finite element analysis of the magnetic field and electromechanical parameters calculation for a slotted permanent magnet tubular linear motor, IEEE Trans. on Magnetics, 43, 3229-3236.

14. Tomczuk B., Waindok A. (2009), Tubular linear actuator as a part of mechatronic system, Solid State Phenomena, 147149, 173-178.

15. Tomczuk B., Waindok A., Wajnert D. (2012), Transients in the electromagnetic actuator with the controlled supplier, Journal of Vibroengineering, 14, 39-44.

16. Wang J., Howe D. (2005), Tubular modular permanent-magnet machines equipped with quasi-Halbach magnetized magnets - Part I: magnetic field distribution, EMF, and thrust force, IEEE Trans. on Magnetics, 41, 2470-2478.

17. Wang J., Howe D., Jewell G.W. (2003), Fringing in tubular permanent-magnet machines: Part II. Cogging force and its minimization, IEEE Trans. on Magnetics, 39, 3517-3522.

18. Wang J., Jewell G.W., Howe D. (1998), A general framework for the analysis and design of tubular linear permanent magnet machines, IEEE Trans. on Magnetics, 35, 1986-1999. 